\title{
La erradicación de Helicobacter pylori en individuos sanos asintomáticos podría reducir la incidencia de cáncer gástrico
}

Eradicating Helicobacter pylori in healthy asymptomatic individuals might reduce the incidence of gastric cancer

Ford AC, y col. Cochrane Database Syst Rev. 2015;7(CD005583).

\section{Objetivos}

Evaluar la efectividad de la erradicación de la infección por $\mathrm{H}$. pylori en individuos sanos y asintomáticos de la población general para reducir la incidencia de cáncer gástrico.

\section{Diseño y fuente de datos}

Meta-análisis de artículos publicados hasta 2013 (MEDLINE, EMBASE, Registro Central de Ensayos Clínicos de la Biblioteca Cochrane, resúmenes publicados de conferencias de la United European Gastroenterology Week, búsqueda manual electrónica de ensayos clínicos y contacto con expertos en la temática).

\section{Selección de los estudios}

Fueron seleccionados ensayos clínicos controlados y aleatorizados que hubieran comparado al menos una semana de terapia contra $\mathrm{H}$. pylori versus placebo o no tratamiento en la prevención del desarrollo subsecuente de cáncer gástrico en pacientes sanos asintomáticos infectados por la bacteria. El seguimiento de los pacientes debía ser de dos años como mínimo y contar con al menos dos participantes que hubieran desarrollado cáncer gástrico. Se definió cáncer gástrico como cualquier adenocarcinoma gástrico, incluyendo las variedades intestinal (diferenciado) o difusa (indiferenciado), con o sin histología especificada.

\section{Extracción de datos}

Los datos fueron extraídos por dos revisores independientes utilizando un análisis por intención de tratar modificado. Las discrepancias fueron resueltas por consenso. Se recogieron datos sobre incidencia de cáncer gástrico, incidencia de cáncer esofágico, muertes por cáncer gástrico, muertes por cualquier causa y eventos adversos secundarios al tratamiento erradicador. Se asumió que todos los participantes perdidos durante el seguimiento no habían desarrollado cáncer gástrico, dada la baja frecuencia del evento de interés. Se realizó asimismo un análisis de sensibilidad en el cual fueron excluidos todos los pacientes que presentaran datos perdidos.

\section{Resultados principales}

Se detallan en la tabla 1

Tabla 1: eficacia de la erradicación del H Pylori sobre la incidencia de cáncer gástrico y esofágico.

\begin{tabular}{|c|c|c|c|c|c|}
\hline Evento de interés & $\begin{array}{c}\mathrm{N}^{\circ} \mathrm{de} \\
\text { participantes } \\
\text { (estudios) }\end{array}$ & $\begin{array}{c}\text { Erradicación } \\
\text { H. pylori } \\
(\%)\end{array}$ & Control & $\begin{array}{l}\text { Efecto Relativo } \\
\text { (IC95\%) }\end{array}$ & Heterogeneidad \\
\hline $\begin{array}{l}\text { Incidencia de cáncer gástrico } \\
\text { Muerte por cáncer gástrico }\end{array}$ & $\begin{array}{l}6497(6) \\
4475(3)\end{array}$ & $\begin{array}{l}51 / 3294(1,6 \%) \\
24 / 2242(1,1 \%)\end{array}$ & $\begin{array}{l}76 / 3203(2,4 \%) \\
36 / 2233(1,6 \%)\end{array}$ & $\begin{array}{c}\operatorname{RR} 0,66(0,46 \mathrm{a} 0,95) \\
\operatorname{RR} 0,67(0,4 \mathrm{a} 1,1)\end{array}$ & $\begin{array}{l}12=0 \% \\
12=0 \%\end{array}$ \\
\hline $\begin{array}{l}\text { Muerte por todas las causas } \\
\text { Incidencia de cáncer esofágico }\end{array}$ & $\begin{array}{l}5253(4) \\
1630(1)\end{array}$ & $\begin{array}{c}192 / 2639(7,3 \%) \\
2 / 817(0,2 \%)\end{array}$ & $\begin{array}{c}175 / 2614(6,7 \%) \\
1 / 813(0,1 \%)\end{array}$ & $\begin{array}{l}\text { RR } 1,09(0,86 \text { a } 1,38) \\
\text { RR } 1,99(0,18 \text { a } 21,91)\end{array}$ & $\begin{aligned} 12 & =6 \% \\
& -\end{aligned}$ \\
\hline $\begin{array}{l}\text { Eventos adversos secundarios al } \\
\text { tratamiento erradicador }\end{array}$ & \multicolumn{5}{|c|}{ os eventos adversos fueron pobremente reportados a lo largo de los estudios y no pudieron ser analizados } \\
\hline
\end{tabular}

IC: Intervalo de confianza; RR: Riesgo relativo. Se considera que la heterogeneidad es inaceptable cuando el I2supera 0,5.

\section{Conclusiones}

Se encontró evidencia limitada y de moderada calidad de que pesquisar y erradicar Helicobacter pylori reduce la incidencia de cáncer gástrico en individuos sanos asintomáticos infectados por esta bacteria, hallazgos que no necesariamente pueden extrapolarse a otras poblaciones.
Conflictos de interés: Moayyedi, P. es coordinador de la junta editorial de la Cochrane Upper . Gastrointestinal and Pancreatic Diseases Group. Sin embargo, las decisiones editoriales sobre esta revisión fueron realizadas por otro coordinador en conjunto con revisores independientes.

\section{Comentario}

El cáncer de estómago es uno de los tumores malignos más frecuentes en el mundo, y constituye la tercera causa de muerte por cáncer con alrededor de 750.000 fallecimientos por año. Su incidencia varía notablemente en diferentes regiones geográficas, siendo significativamente mayor en los países asiáticos como China y Japón. En América Latina, los países con mayor mortalidad por esta neoplasia son Chile, Costa Rica y Ecuador, mientras que Argentina presenta tasas menores a la media'. Estudios epidemiológicos han demostrado una fuerte asociación entre la infección por Helicobacter pylori y el desarrollo de cáncer gástrico a tal punto de considerar al patógeno como agente carcinógeno para el ser humano². La revisión que hemos resumido previamente sugiere que pesquisar y erradicar H.pylori en individuos sanos asintomáticos de la población general reduce la incidencia de cáncer gástrico en un 34\%, siendo necesario erradicar dicha bacteria en 124 individuos para evitar un caso de dicha neoplasia. Este efecto observado pemaneció estable incluso luego de distintos análisis de sensibilidad realizados, aunque no se pudo confimar o refutar si el beneficio de la erradicación depende de la presencia o ausencia de lesiones pre-neo- plásicas previas. Asimismo, no se demostró impacto en la reducción de la mortalidad por todas las causas, aunque debe tenerse en cuenta que la incidencia de cáncer gástrico es baja con respecto a otras patologías y se requeriría una muestra extremadamente grande para observar una diferencia estadísticamente significativa. Es importante resaltar que cinco de los seis estudios analizados fueron llevados a cabo en poblaciones asiáticas, en las que la incidencia de cáncer gástrico es más elevada que en poblaciones occidentales; y que particularmente en el trabajo desarrollado en Sudamérica, no logró evidenciarse beneficio del tratamiento erradicador.

\section{Conclusión del comentador}

Si bien la erradicación de la infección por H. pylori en individuos sanos asintomáticos de la población general sería eficaz para reducir la incidencia de cáncer gástrico en poblaciones asiáticas, esto no puede extrapolarse por el momento al resto del mundo, por lo cual en Argentina recomendamos emplear esta estrategia solo en los individuos con alto riesgo de desarrollar cáncer gástrico y no en la población general.

Alejandro Rey [ Servicio de Gastroenterología del Hospital Italiano de Buenos Aires. alejandro.rey @ hiba.org.ar ]

Rey A. La erradicación de Helicobacter pylori en individuos sanos asintomáticos podría reducir la incidencia de cáncer gástrico. Evid Act Pract Ambul. 2016;19(1):7. Ene-Mar. Comentado de: Ford AC, y col. Helicobacter pylori eradication for the prevention of gastric neoplasia. Cochrane Database Syst Rev. 2015;7(CD005583). PMID: 26198377.

\section{Bibliografia}

1. Jemal A y col. Global cancer statistics. CA Cancer J Clin. 2011 Jan 4;61(2):69-90.

2. Schistosomes, liver flukes and Helicobacter pylori. IARC Working Group on the Evaluation of Carcinogenic Risks to Humans. Lyon, 7-14 June 1994. IARC Monogr Eval Carcinog Risks Hum. 1994 Jan;61:1-241. 